\title{
ASENTAMIENTO, AGRICULTURA Y PASTORALISMO DURANTE EL PERIODO FORMATIVO EN EL VALLE DEL COLCA, PERÚ
}

\author{
SETTLEMENT, AGRICULTURE, AND PASTORALISM DURING \\ THE FORMATIVE PERIOD IN THE COLCA VALLEY, PERU
}

\begin{abstract}
Steven A. Wernke
Este artículo presenta una visión preliminar de la ocupación formativa en el valle del Colca, ubicado en la sierra suroccidental peruana. A partir de datos recuperados de una prospección sistemática de la parte central del valle, se define por primera vez el patrón de asentamiento del periodo Formativo. Se presenta un resumen descriptivo de un estilo de cerámica local asociada con la ocupación formativa, y se caracteriza la naturaleza de los asentamientos de agricultores y pastores tempranos, junto con una discusión de los complejos agrícolas ubicados en las laderas y en el fondo del valle. El patrón de asentamiento se caracteriza por una ocupación dispersa de pequeñas aldeas, sin índices de centralización política o desigualdades económicas. Sin embargo, hay evidencia de infraestructura agrícola en la forma de grandes y complejos recintos amurallados "agro-mortuorios" en el fondo del valle, que se caracterizan por gruesas murallas y que integran cistas mortuorias y silos alrededor de campos de cultivo. A diferencia de estudios anteriores que sugirieron que la agricultura temprana en el valle del Colca se desarrolló mayormente en las zonas superiores de las laderas, los resultados que aquí se presentan muestran una modificación antropogénica inicial con fines agrícolas tanto en las extensas pampas del fondo del valle como en sus laderas.
\end{abstract}

Palabras claves: arqueología, periodo Formativo, valle del Colca, patrones de asentamiento agricultura, paisaje.

This article presents a preliminary view of the Formative occupation of the Colca Valley, located in the southwestern Peruvian highlands. Based on data recovered from a systematic survey of the central part of the valley, the Formative Period settlement pattern for the Colca Valley is defined for the first time in this valley. A summary description of a ceramic style associated with the Formative is presented, and the nature of agriculturalist and pastoralist settlements is characterized, together with a discussion of the associated agricultural complexes on the valley slopes and bottom. Overall, the settlement pattern is characterized by a dispersed occupation of small settlements, without indices of political centralization or economic inequalities. But there is evidence for early elaboration of the notable agricultural infrastructure of the valley during the Formative, in the form of large complexes of "agro-mortuary" wall on the valley bottom. These are characterized by wide and high walls with mortuary features (cist tombs) and silos, which enclose agricultural fields. In contrast to prior studies, which suggest that early agriculture in the Colca Valley was more focused on the upper slopes, these results confirm the initial anthropogenic modification of the extensive pampas of the valley bottom, and the elaboration of sloping fields on the valley sides.

Key words: Archaeology, Formative Period, Colca Valley, agriculture, settlement patterns, landscape.

El período Formativo en la región surandina del Perú se define por una serie de transformaciones sociales importantes que establecieron los parámetros básicos para desarrollos culturales subsecuentes. Durante la transición entre el Arcaico Terminal y el Formativo Temprano se registran los primeros indicios de una producción agrícola y del pastoreo, asociados con el sedentarismo, la producción de cerámica y con crecientes redes de intercambio (Aldenderfer 1998; Bandy 2004a, 2004b; Stanish et al. 2002). Durante el Formativo Medio y Tardío se desarrollaron los primeros estilos corporativos a nivel regional, junto a los primigenios indicios de marcadas desigualdades sociales y la centralización política, procesos que convergieron en la formación de Tiwanaku, el primer Estado en la región (Chávez 1988; Chávez 1992; Hastorf 1999; Janusek 2004, 2008; Klarich 2005; Kolata 1993).

A pesar de la importancia fundamental del Formativo para la comprensión de la trayectoria de los Andes del sur en el largo plazo, este período ha sido muy poco conocido o investigado en el valle del Colca. Irónicamente, se sabía más de la amplia distribución de obsidiana proveniente de la

1 Department of Anthropology, VU Station B \#356050, Vanderbilt University, Nashville, Tennessee, U.S.A.

s.wernke@ vanderbilt.edu 
fuente de Chivay (Brooks 1998; Brooks et al. 1997; Burger et al. 1998; Burger et al. 2000; Stanish et al. 2002; Tripcevich 2007; Tripcevich y Mackay 2011; Tripcevich y Yépez 2009) que de la existencia humana en el mismo valle. La presencia de esta obsidiana por toda la región revela vastas redes de intercambio y la existencia de lazos especialmente fuertes con la región altiplánica desde, por lo menos, la época Arcaica Tardía (4.800-3.000 a.C.) (Burger et al. 1998; Burger et al. 2000; Stanish et al. 2002; Tripcevich 2007; Tripcevich y Yépez 2009). Estos indicios concuerdan con los modelos generales acerca de la importancia del intercambio regional y de los caravaneros en el desarrollo de la complejidad cultural durante el Formativo en la región altiplánica y zonas aledañas (Browman 1981; Dillehay y Núñez 1988). Evidentemente, el Colca constituyó un núcleo clave en estas redes de intercambio desde el período Arcaico y, probablemente, fue un centro de asentamiento de importantes poblaciones arcaicas y formativas (Tripcevich 2007; Tripcevich y Yépez 2009). Considerando la importancia fundamental del período Formativo en la comprensión de la trayectoria cultural de largo plazo de los Andes del Sur, y la importancia del valle del Colca en las redes económicas regionales durante dicho tiempo, este vacío es crítico en nuestro conocimiento.

En el presente artículo se presenta la evidencia de una importante ocupación del Formativo en la parte central del valle del Colca, lo que pareciera representar el período más temprano de asentamiento agrícola y agropastoril del valle. Los datos provienen de una prospección sistemática de $90 \mathrm{~km}^{2}$ realizada por el autor en la zona circundante a los pueblos de Yanque y Coporaque, una zona donde se desarrolló el núcleo político de la etnia collagua durante el periodo Intermedio Tardío y el Horizonte Tardío (Figura 1) (Wernke 2003, 2006a, 2006b, 2007, 2009). Aunque posteriores ocupaciones y modificaciones extensivas del paisaje complican su registro e interpretación, la prospección ha documentado una significativa ocupación formativa caracterizada por un patrón de pequeños asentamientos asociados a chacras en pendiente, en las faldas del valle, y complejos extensivos de chacras y muros sobre el fondo del mismo.

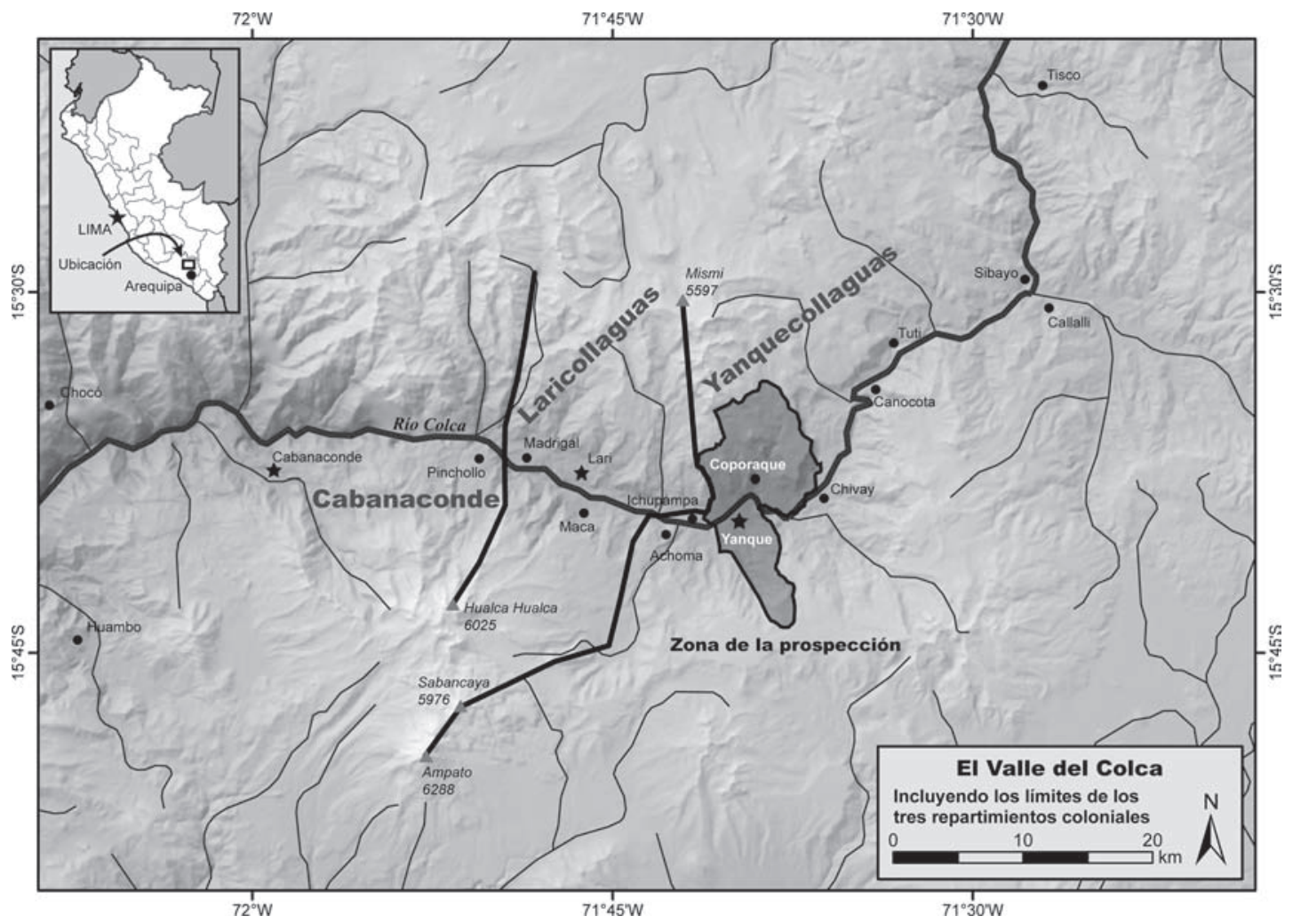

Figura 1. Ubicación del área de la prospección.

Location of the survey area. 
Dado que este trabajo documenta, por primera vez, un componente del período Formativo en el Colca, el análisis es más bien conservador en términos de interpretación. Se necesitan investigaciones más precisas para poder comprender la cronología y las causas de los inicios de la agricultura, el sedentarismo y la diferenciación social.

\section{Consideraciones Espaciales y Cronológicas}

Como los datos provienen de una prospección superficial, la demarcación de los sitios del período Formativo se ha complicado por dos factores: Primero, las terrazas domésticas y agrícolas y la arquitectura, en muchos casos, fueron sobrepuestas por ocupaciones posteriores, obliterando así sitios pequeños y complicando la delimitación del área ocupacional de los componentes del periodo. Segundo, probablemente como consecuencia de posteriores ocupaciones, en la mayoría de los sitios las densidades de los artefactos superficiales formativos son muy limitadas. Quizás por esta razón no se han identificado componentes formativos en otras investigaciones realizadas en el valle (Brooks 1998; de la Vera Cruz Chávez 1987, 1988, 1989; Denevan 2001; Malpass y de la Vera Cruz Chávez 1990; Neira Avendaño 1961, 1986; Oquiche Hernani 1991; Shea 1987; Treacy 1994), teniendo en cuenta también que éstas se centraron mayormente en las ocupaciones más tardías del Intermedio Tardío y del Horizonte Tardío. La modificación intensiva del valle por medio de la andenería durante los periodos tardíos también explicaría la relativa escasez de rasgos formativos en superficie, en relación al área circunlacustre, donde las ocupaciones formativas generalmente son más densas y visibles, permitiendo su delimitación más confiable en superficie (por ejemplo, entre otros: Bandy 2001; Janusek y Kolata 2004; Stanish 1997, 2003).

En nuestra prospección se recuperaron, en la mayoría de los sitios, menos de diez artefactos (y en algunos casos menos de cinco) del período Formativo, permitiendo sólo bosquejar los límites de componentes específicos en algunos sitios multicomponentes. Por lo tanto, con notables excepciones (que se analizan más adelante), en la mayoría de los casos no se ha determinado, con precisión, el cálculo de las áreas.

En este estado preliminar de las investigaciones del período Formativo en el valle, el control cronológico todavía permanece burdo. Con anterioridad a este proyecto la cronología cerámica local, presentada por Malpass y de la Vera Cruz (de la Vera Cruz Chávez 1987, 1988, 1989; Malpass y de la Vera Cruz Chávez 1990) y elaborada por Brooks (1998), abarcaba desde del Horizonte Medio hasta el Horizonte Tardío. Brooks (1998) señaló la presencia de un posible alfar pre-Horizonte Medio, al cual denominó el estilo "Japo", pero la muestra era pequeña y variable entre sí. En las colecciones de nuestra prospección hemos identificado una cerámica que la consideramos ampliamente diagnóstica del período Formativo, denominada cerámica "Chiquero". A diferencia de otros estilos formativos decorados de la región arequipeña, como los identificados por Neira y Cardona Rosas (Cardona Rosas 2002; Neira Avendaño 1990; Neira Avendaño y Cardona Rosas 2000-2001), la cerámica Chiquero es un alfar utilitario sin decorar que no permite, al presente, realizar fechados cruzados con estilos formativos vecinos. Pero como luego se explicará, nuestra clasificación de la cerámica Chiquero, como un alfar perteneciente al Formativo (definido ampliamente como el período entre 1.500 a.C. hasta 500 d.C.), se basa en la semejanza general de sus rasgos morfológicos y técnicas de producción con los atributos similares en alfares formativos de otros sitios de la región. Hasta la fecha se ha recuperado cerámica con rasgos semejantes al estilo Chiquero en un solo contexto estratigráfico, procedente de un pozo de prueba excavado por Nicholas Tripcevich en la puna circundante del valle (2007:577, 611612). Tripcevich presenta una fecha radiocarbónica asociada de 654-772 cal d.C. $(p=0,95)$ (calibrados a 2 sigmas con el programa Calib 6.0) (AA56939, ver Tripcevich 2007:611), sugiriendo una posible continuidad de uso de un alfar semejante hasta el Horizonte Medio en la zona de pastoreo, aunque no se puede precisar si este fechado representa el rango tardío de su uso. Lo cierto, como se argumentará, es que la cerámica Chiquero está asociada con las ocupaciones agrícolas tempranas en la parte central del valle del Colca, y fue reemplazada -probablemente en forma paulatina-por los alfares locales del Horizonte Medio. No se han aislado puntas de proyectil exclusivamente diagnósticas del período Formativo; sin embargo, existen puntas que parecen ser ampliamente diagnósticas de las épocas del Arcaico Terminal y Formativo (ver abajo). Se han recuperado ejemplares de este tipo de puntas en cinco sitios de la prospección, y se incluyen en el análisis. Por lo tanto, el patrón de 
asentamiento analizado representa un palimpsesto de ocupaciones.

\section{El Patrón de Asentamiento del Período Formativo en la Zona Central del Valle del Colca}

A pesar de estas complicaciones, la prospección inequívocamente ha identificado, en la parte central del valle del Colca, una ocupación del período Formativo. Se documentó un total de 30 sitios de este período, incluyendo un asentamiento agrícola de considerable extensión (YA-032), así como una serie de sitios más pequeños en ambas márgenes del valle y en la puna, tanto en abrigos rocosos como en contextos al aire libre. De estos 30 sitios, 21 se clasificaron como asentamientos (incluyendo dispersiones y montículos), cinco sitios como "complejos agro-mortuorios", tres como abrigos rocosos y uno como cementerio (Figuras 2 y 3, Tabla 1).

Todos los contextos geográficos y ecológicos en el valle fueron ocupados o explotados durante el Formativo; sin embargo, los asentamientos claramente se concentraron en elevaciones por debajo del área de prospección (Figuras 2-3). De los 21 sitios clasificados como asentamientos, 13 (11 en la zona kichwa y 3 en la suni) se ubican entre la amplia terraza aluvial sobre el río y las laderas circundantes. Aunque la mayoría de los sitios en los recodos bajos del valle se concentran hacia el lado norte del río, el asentamiento Formativo más grande en la prospección (YA-032, Chiquero) se ubica sobre un promontorio sobre el piso del valle hacia el lado sur del río (ver abajo). En la puna, se identificaron siete sitios al aire libre y tres sitios en abrigos rocosos, conteniendo cerámica formativa y/o puntas arcaicas terminales o formativas. De estos diez sitios de la puna, todos, excepto tres (dos pequeños sitios al aire libre: CO-152 y CO-159; y un pequeño abrigo rocoso: YA-082), produjeron también puntas de proyectil del período Arcaico Tardío o Arcaico Terminal, indicando una considerable continuidad, desde patrones de caza y recolección más antiguos. Los sitios de la puna se concentran alrededor de bofedales y quebradas -los principales lugares de concentración de recursos y agua en la zona.

Los sitios se diferencian por su contexto, tamaño y densidad y tipos de artefactos. No existe evidencia de rasgos arquitectónicos corporativos (por ejemplo, rasgos de montículos formales) u otros índices de desigualdades económicas o políticas durante este periodo. Donde se pueden delimitar las áreas ocupacionales, no se evidencia una jerarquía de tamaños de los sitios. La cerámica Chiquero no es decorada, y se descubrió sólo un fragmento formativo decorado del estilo Pukara (ver abajo). Sobre todo, el patrón de asentamiento en la zona agrícola del área de prospección indica que la población estaba distribuida entre una serie de pequeñas aldeas agrícolas, tal vez concentradas en el fondo del valle.

Queda aún por clarificarse las relaciones entre los asentamientos agrícolas de las zonas bajas del valle y los sitios de la puna, aunque se pueden señalar algunas posibilidades de sus formas de interacción. Por un lado, la evidencia de la caza y posiblemente del pastoreo en la puna durante el Formativo podrían representar los residuos de grupos involucrados en una economía mixta de pastoreo y caza, o de expediciones de caza realizadas por los agricultores, o una mezcla de ambos escenarios. A pesar que el control cronológico todavía es burdo, también es posible que hubiese cambios diacrónicos entre estos patrones. Además, la presencia de puntas de proyectil en el asentamiento más grande de Chiquero (YA-032; ver abajo) sugiere que, por lo menos, durante una parte del Formativo los agricultores también se involucraban en la caza. Pero las puntas recuperadas de YA-032 son ampliamente diagnósticas del Arcaico Terminal hasta el Horizonte Tardío, de modo que pudieron pertenecer a cualquiera de estos períodos de ocupación o a varios. La ausencia general de un control cronológico impide una mayor clarificación de estas complejas y seguramente cambiantes relaciones interzonales.

\section{Sitio YA-032: Chiquero}

El sitio Chiquero (YA-032) domina el patrón de asentamiento en términos de tamaño y cantidad de artefactos diagnósticos recuperados. El sitio se ubica encima de una cresta prominente que desciende desde el borde de la puna, proporcionando vistas panorámicas sobre la amplia pampa hacia el oeste del pueblo de Yanque (Figuras 2 y 8). Una capilla moderna (dedicada a la Virgen de Chapi) y una plaza adjunta ocupan la cumbre de este cerro. Aunque la capilla y la plaza oscurecen los rasgos que hubieran estado presentes en lo que fue probablemente el sector central del sitio, su función como un asentamiento agrícola es evidente a partir 


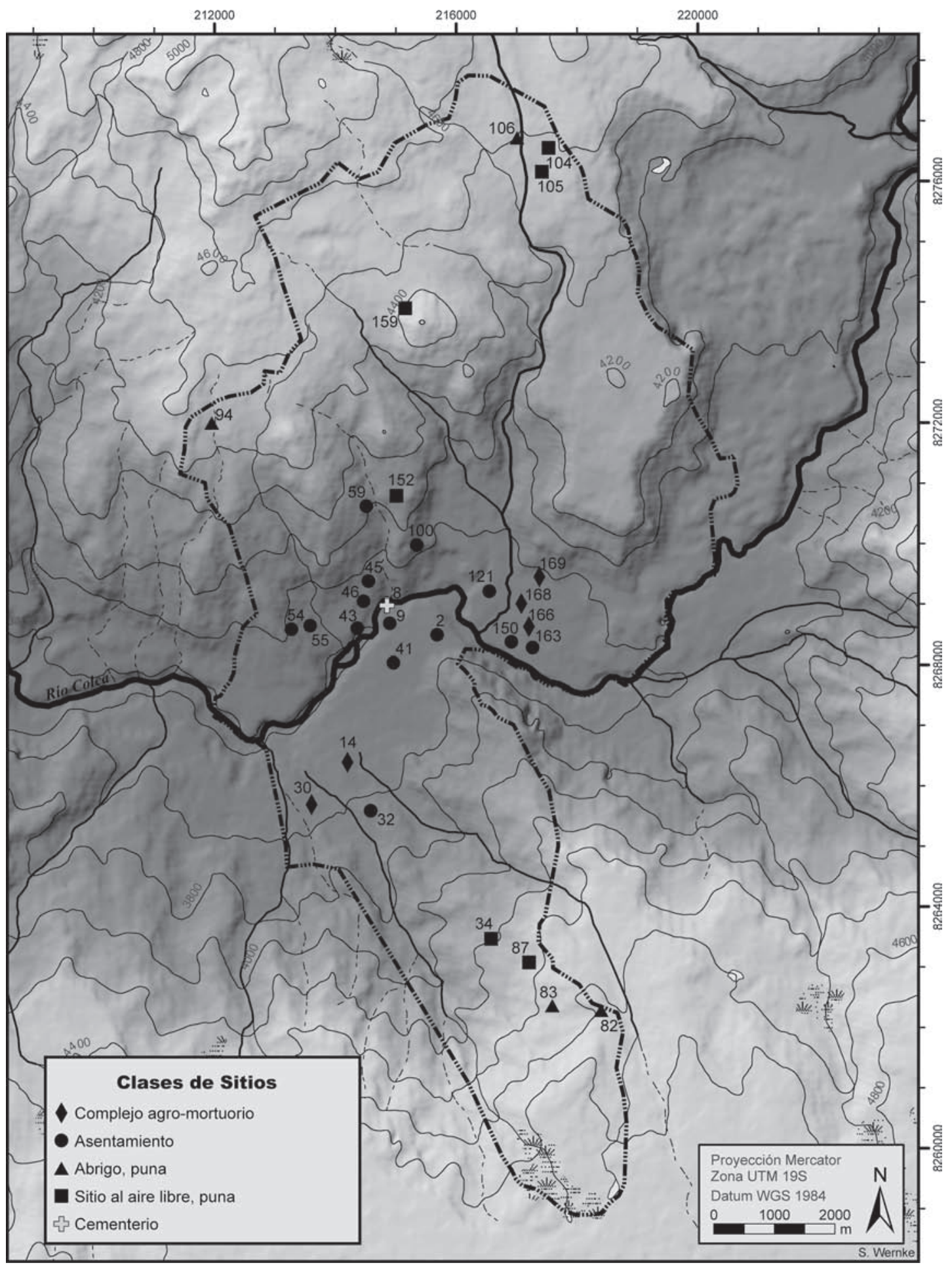

Figura 2. Mapa de los sitios del período Formativo en el área de la prospección. Map of the Formative Period sites in the survey area. 
Tabla 1. Sitios formativos registrados $(\mathrm{n}=30)$. Formative sites registered $(n=30)$.

\begin{tabular}{|c|c|c|c|c|c|}
\hline $\mathbf{N}^{0}$ Sitio & Sector(es) & Elevación & Zona & Clase de sitio & Área \\
\hline YA-002 & $\mathrm{A} / \mathrm{B}$ & 3495 & Kichwa & Dispersión/montículo indefinido & 0,06 \\
\hline YA-008 & $\mathrm{C}$ & 3403 & Kichwa & Cementerio pequeño & 0,04 \\
\hline YA-009 & $\mathrm{B}$ & 3478 & Kichwa & Dispersión pequeña & $?$ \\
\hline YA-014 & & 3533 & Kichwa & Complejo agro-mortuorio & $?$ \\
\hline YA-030 & & 3575 & Kichwa & Complejo agro-mortuorio & $?$ \\
\hline YA-032 & & 3665 & Suni & Dispersión grande & 3,88 \\
\hline YA-034 & & 4187 & Puna & Dispersión grande & 2,19 \\
\hline YA-041 & & 3484 & Kichwa & Dispersión pequeña & $?$ \\
\hline YA-043 & & 3417 & Kichwa & Dispersión/montículo indefinido & 0,01 \\
\hline YA-045 & & 3556 & Kichwa & Dispersión pequeña & 1,51 \\
\hline YA-046 & & 3494 & Kichwa & Dispersión pequeña & 0,34 \\
\hline YA-054 & & 3572 & Kichwa & Dispersión pequeña & 1,75 \\
\hline YA-055 & & 3485 & Kichwa & Dispersión pequeña & 0,03 \\
\hline YA-059 & & 3808 & Suni & Dispersión pequeña & 0,25 \\
\hline YA-082 & & 4623 & Puna & Abrigo pequeño & 0,01 \\
\hline YA-083 & & 4467 & Puna & Abrigo pequeño & 0,01 \\
\hline YA-087 & & 4337 & Puna & Dispersión pequeña & 0,09 \\
\hline YA-094 & $\mathrm{B} / \mathrm{C}$ & 4254 & Puna & Abrigo pequeño & 0,04 \\
\hline CO-100 & & 3666 & Suni & Dispersión pequeña & $?$ \\
\hline CO-104 & & 4362 & Puna & Dispersión pequeña & 0,01 \\
\hline CO-105 & & 4348 & Puna & Dispersión pequeña & 0,06 \\
\hline CO-106 & & 4397 & Puna & Abrigo grande & 0,10 \\
\hline CO-121 & & 3537 & Kichwa & Dispersión/montículo indefinido & 0,01 \\
\hline $\mathrm{CO}-150$ & $\mathrm{~B} / \mathrm{C}$ & 3513 & Kichwa & Dispersión/montículo indefinido & 0,15 \\
\hline $\mathrm{CO}-152$ & & 3884 & Puna & Dispersión pequeña & 0,18 \\
\hline CO-159 & & 4419 & Puna & Dispersión pequeña & 0,36 \\
\hline $\mathrm{CO}-163$ & & 3528 & Kichwa & Dispersión pequeña & $?$ \\
\hline CO-166 & & 3545 & Kichwa & Complejo agro-mortuorio & $?$ \\
\hline CO-168 & & 3547 & Kichwa & Complejo agro-mortuorio & $?$ \\
\hline CO-169 & & 3568 & Kichwa & Complejo agro-mortuorio & $?$ \\
\hline
\end{tabular}

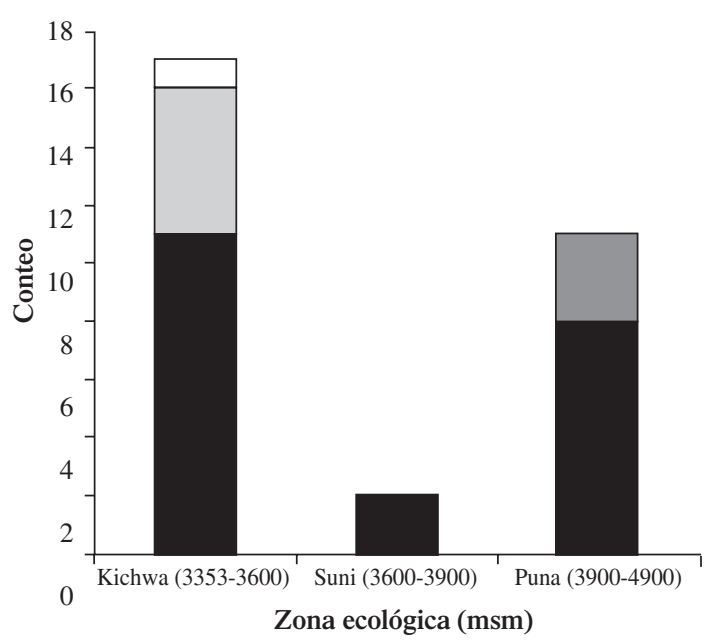

\begin{tabular}{|l|l|}
$\square$ Cementerio & $\square$ Abrigo \\
$\begin{array}{l}\square \text { Complejo } \\
\text { agro-mortuorio }\end{array}$ & $\square$ Asentamiento/dispersión \\
\hline
\end{tabular}

Figura 3. Sitios formativos por zona ecológica $(\mathrm{n}=30)$. Formative sites by ecological zone $(n=30)$. de los abundantes artefactos domésticos y agrícolas presentes, incluyendo cerámica utilitaria, batanes y azadas de basalto. Una dispersión cerámica y lítica extensa cubre las 3,88 hectáreas del área del sitio.

El contexto ecológico también parece significativo. A $3.665 \mathrm{msm}$, el sitio se ubica en la zona suni, el ecotono entre las zonas kichwa y puna, adyacente a un importante camino que sigue a través de las quebradas principales sobre el borde del valle para unirse a redes de senderos que llevan hacia Arequipa y Yura hacia el sur y Lluta, Huanca y Huambo hacia el suroeste. Asumiendo que los caminos antiguos seguían estas mismas rutas de menor resistencia hacia fuera del valle, el sitio pudo estar bien ubicado como un punto de articulación entre diversas zonas de producción a nivel regional.

Chiquero es el sitio tipo para la cerámica del período Formativo, habiendo producido el 64\% del total de los fragmentos diagnósticos recolectados para el período $(n=97$ de 152). El conjunto de la cerámica Chiquero está dominado por ollas 


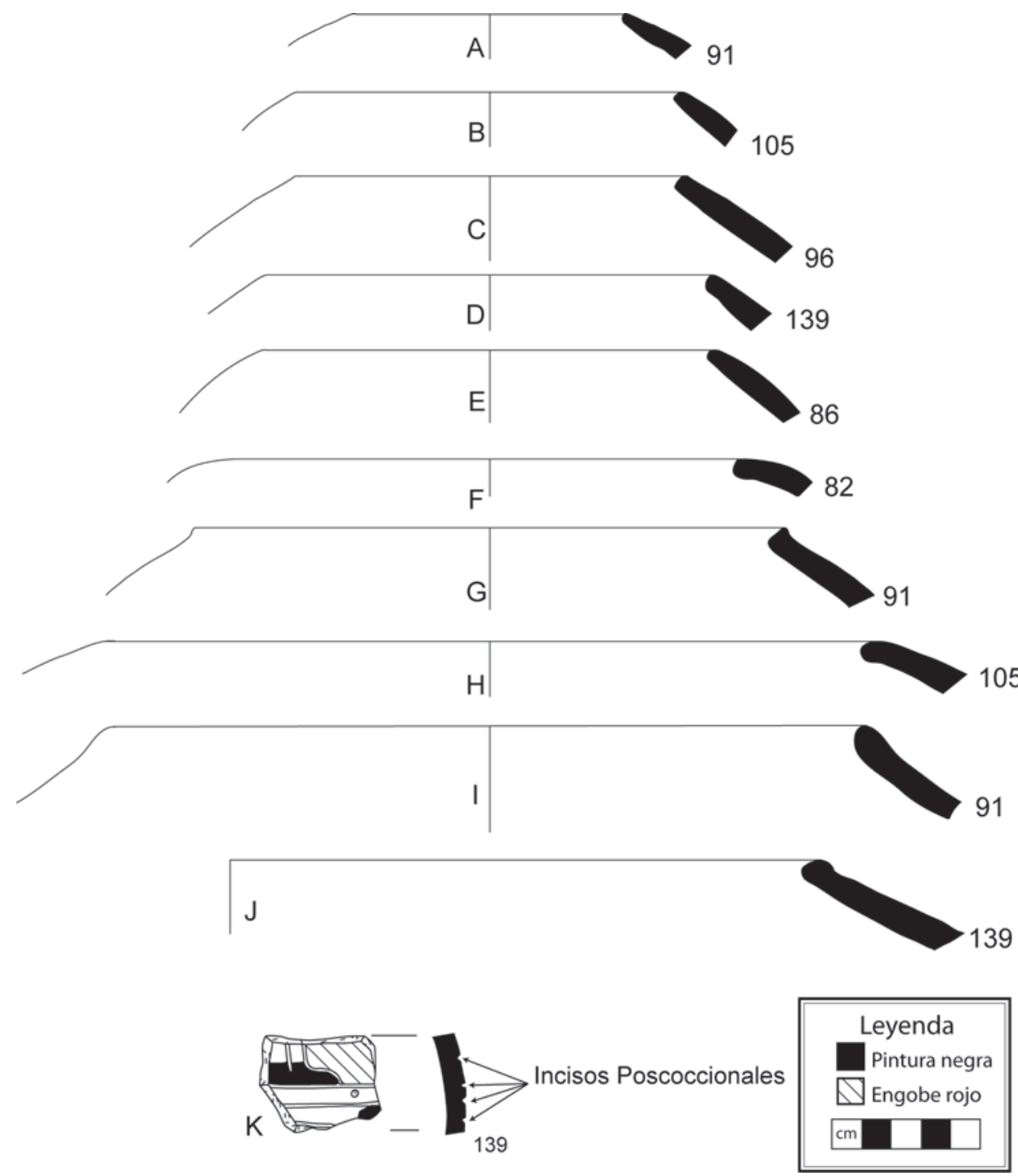

Figura 4. Cerámica formativa procedente de YA-032 (los códigos indican el número del lote de colección). Formative ceramics from YA-032 (the codes indicate collection lot numbers).

esferoides sin cuello - la forma típica del Formativo en la región- pero también contiene cantidades de otras ollas y formas con orificios restringidos (Figura 4, A-J). Es un alfar sin engobe con marcadas estriaciones superficiales en el interior y exterior, huellas de una técnica de escobillado con una tosca fibra vegetal (Figura 5). También se recuperó un fragmento del estilo Pukara Clásico con un motivo zoomórfico inciso postcocción (probablemente una pata de camélido). Este fragmento provee una medida de control temporal, indicando que el sitio estaba ocupado entre los 200 a.C. y 400 d.C. (Klarich 2009), aunque la duración de la ocupación probablemente se extendió considerablemente hacia ambos lados de estas fechas.

Los artefactos líticos recuperados de la superficie del sitio incluyen batanes, raspadores, puntas de proyectil y azadas, indicando que los habitantes del sitio estaban involucrados en la caza, el cultivo y las tareas domésticas (Figuras 6 y 7). Se encontraron por todo el sitio, en grandes concentraciones, desechos de talla y puntas de proyectil. Las cinco puntas de proyectil (Puntas tipo 5D en la cronología regional, Figura 6) son ampliamente diagnósticas de tiempos del Arcaico Terminal hasta el Horizonte Tardío, pero son más prevalentes en los componentes del 


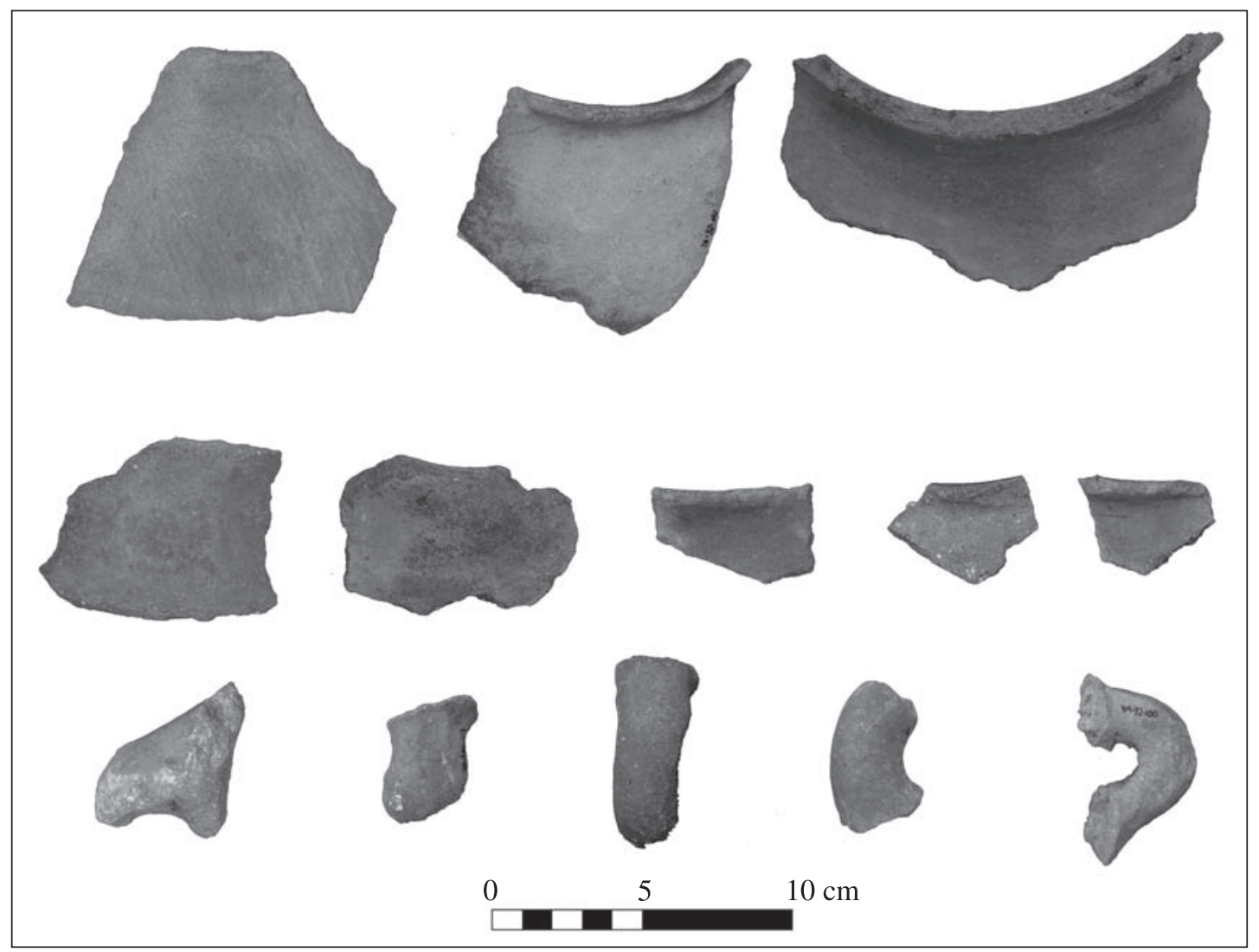

Figura 5. Fragmentos de cerámica Chiquero.

Fragments of Chiquero ceramics.

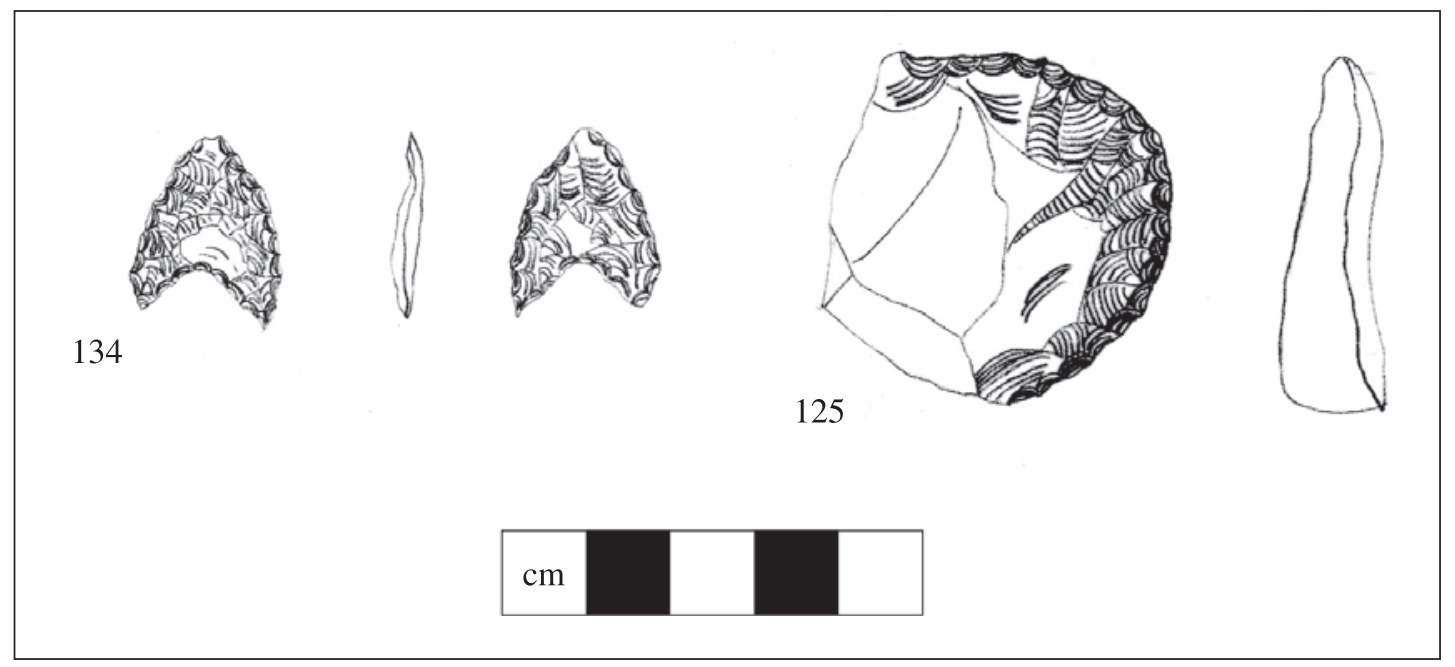

Figura 6. Punta de proyectil Tipo 5D y raspador procedente de YA-032 (se indica el número del lote). Type 5D projectile point and scraper from YA-032 (lot numbers indicated). 


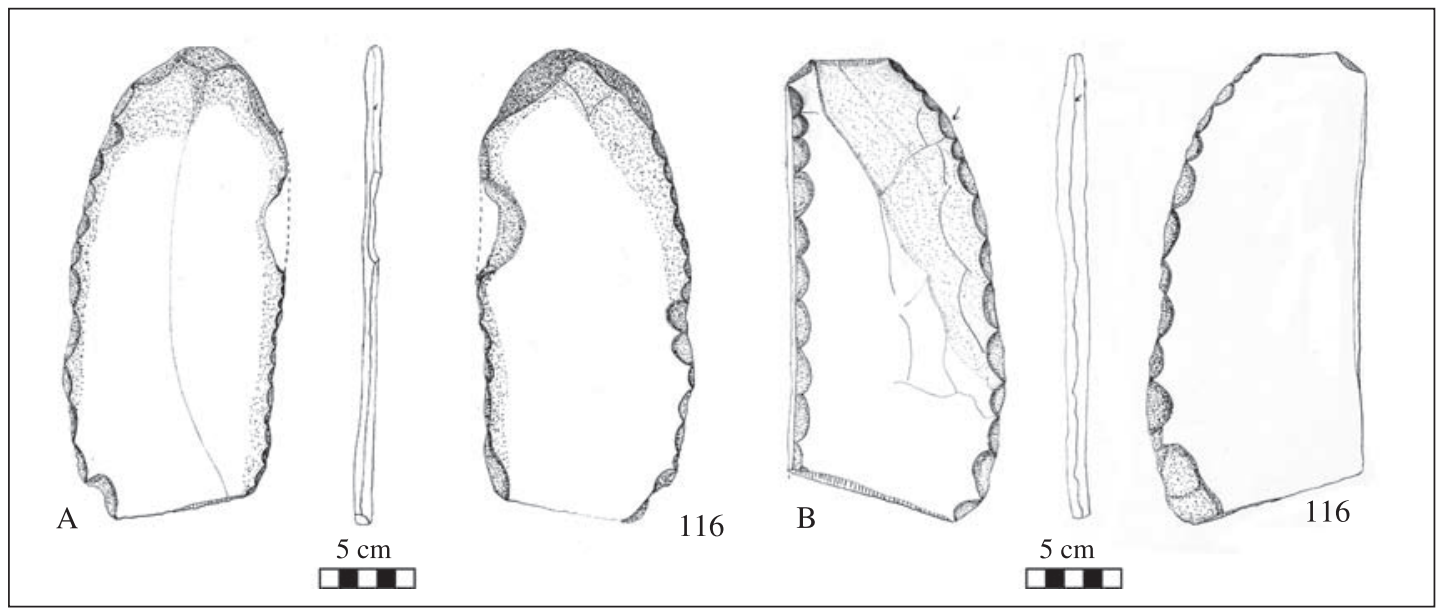

Figura 7. Azadas de basalto procedentes de YA-032 (se indica el número de lote).

Basalt hoes from YA-032 (lot numbers indicated).

Formativo (especialmente del Formativo Tardío) en la región (Klink y Aldenderfer 2005). La densidad de azadas de basalto disminuye dramáticamente en los contextos postformativos a lo largo de los Andes sur-centrales, a medida que otros materiales (probablemente perecederos) reemplazaron a esta tecnología lítica, y así parece ser, también, en el Colca. Durante la prospección, no se recuperaron azadas líticas de sitios sin cerámica del período Formativo, indicando que constituyen una clase de artefactos ampliamente diagnósticos de la época.

En Chiquero, la muestra grande $(\mathrm{N}=69)$ de azadas recuperadas señala que los habitantes del sitio practicaban el cultivo agrícola (Figura 7). La alta densidad de azadas en el sitio puede reflejar, en parte, una explotación oportunista de los abundantes filones de basalto que se encuentran en superficie. Sin embargo, el sitio no fue solamente un taller lítico, puesto que la evidencia del desgaste, pulido y estriaciones de uso en sus extremos distales indican que los implementos fueron usados y no sólo elaborados localmente. Estas azadas de basalto son muy similares en tamaño y forma a los recuperados en contextos del período Formativo por toda la cuenca del Pacífico sur y en la cuenca del Titicaca (Bandy 2001; Stanish 1997; Stanish et al. 1994).

\section{La Producción Agrícola y la Modificación del Paisaje durante el Formativo}

Hay evidencia indirecta acerca del tipo de agricultura practicada por los habitantes de Chiquero y la infraestructura agrícola de aquel tiempo. Se puede precisar, en parte por eliminación, el régimen agrícola, ya que los complejos de terrazas con riego que rodean el sitio son claramente posteriores a la ocupación formativa. Esto es evidente en la distribución de los artefactos formativos en Chiquero, que se trunca a lo largo del perímetro norte del sitio por las terrazas con riego, indicando que se sobreponen a la ocupación formativa. Más precisamente, sólo se revela la ocupación formativa entre andenes irrigados abandonados, donde la erosión ha revelado las subyacentes dispersiones de artefactos (Figura 8). Aparentemente, el sitio se extendía sobre la superficie de la ladera original del cerro, o estaba compuesto de terrazas domésticas que más tarde fueron ocultadas por los andenes irrigados. Así, estos andenes proporcionan un fechado post quem para la ocupación del sitio.

Los habitantes de Chiquero probablemente cultivaron sus chacras en las laderas sin riego, como aquellas que ocupan 14 ha inmediatamente por encima del sitio en las laderas de una meseta (denominada Senja Pata). Estas chacras poseen la misma morfología que las identificadas por Brooks y Treacy como predecesoras de las terrazas irrigadas de Coporaque y Chivay (Brooks 1998; Treacy 1994). De manera semejante al patrón de aumentación, o "cosecha" de aguas de drenaje documentado en Coporaque por Treacy (1994:102-109), parece que la ubicación y orientación de este complejo de chacras se aprovechó del patrón de drenaje natural de la cumbre y de las laderas superiores. Dada la asociación del complejo Coporaque y Chivay y el ejemplar de Chiquero, es razonable sugerir que los 


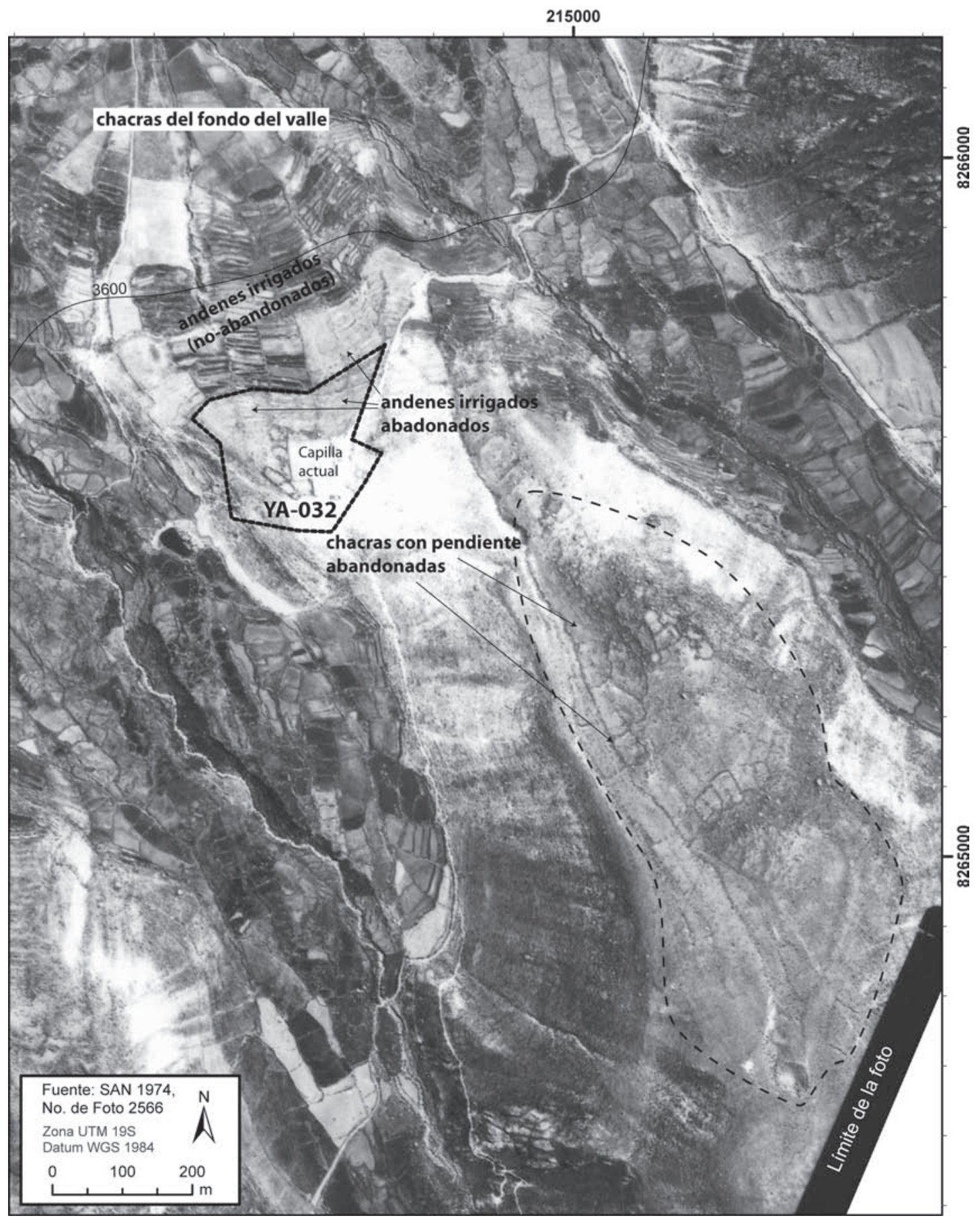

Figura 8. YA-032 (Chiquero) y rasgos del paisaje circundantes. YA-032 (Chiquero) and surrounding landscape features.

habitantes de Chiquero estuviesen involucrados en este tipo de agricultura de secano, aquí y en otras chacras de las laderas circundantes, muchas de las cuales después fueron reemplazadas por complejos de terrazas en banca.
En el fondo del valle, aparte de las dispersiones de artefactos, la identificación de evidencias directas de una temprana producción agrícola está impedida por la modificación postformativa del paisaje. Sin embargo, la prospección logró identificar una 
clase importante de rasgos agrícolas y mortuorios que parecen haberse originado en el Formativo. Específicamente, se registraron grandes complejos de muros que dividen las chacras y cubren amplias áreas de la superficie de las pampas sobre ambos lados del río. La expansión de estos complejos sobre áreas muy grandes fue sin duda un proceso largo y complejo, pero sus configuraciones irregulares sugieren un proceso gradual y aglutinador. $\mathrm{La}$ cerámica recuperada en estos muros, de rasgos discretos, indica que su período de construcción y uso fue continuo desde el Formativo hasta el Horizonte Tardío (ver Doutriaux 2004:175-179; Wernke 2003). Nosotros hemos denominado a estos complejos "murallas agro-mortuorias" porque parecen cumplir funciones tanto agrícolas como mortuorias. Semejantes complejos han sido descritos en el sitio Achachiwa en Cabanaconde por de la Vera Cruz (1987) y recientemente en Lari por Miriam Doutriaux (2004:175-179).

Estos complejos se componen de muros largos y extremadamente anchos, formando un patrón "celular" en vista de planta. Chacras agrícolas ocupan las "células", variando entre 10-25 m de ancho y 10-50 m de largo (Figura 9). El rasgo más impresionante es lo masivo de estos complejos. Son altos, variando entre 4 y 5 metros de altura, y extremadamente anchos, un promedio de $2 \mathrm{~m}$, inclusive llegando a grosores de $10 \mathrm{~m}$ en algunos puntos de intersección, como se observa en la Figura 10. Así, sus superficies superiores forman amplias y altas plataformas. Los muros están compuestos por revestimientos de piedras de campo no trabajados, y un relleno distinto de cascajo y tierra (Figura 10). Así, parece que fueran formados por un aluvión que hubiese cubierto la superficie, y funcionaron, en parte, como un receptáculo de las piedras arrojadas allí luego de limpiar el suelo para facilitar el cultivo. Sin embargo, no se puede explicar su construcción solamente por esta estrecha función agrícola.

Como se observa en la Figura 10, se encuentran rasgos circulares y ovoides de tamaños variados a lo largo de la ancha superficie de las cimas de los muros. Algunos son tumbas (cistas), mientras que otros fueron, probablemente, espacios de almacenamiento. Parece haber por lo menos dos clases de rasgos circulares-ovoides: una clase más pequeña, de diámetros entre 0,5-1,0 m, que parecen cistas, y una clase más grande, de diámetros promedio de $2 \mathrm{~m}$, que parecen tener la función de almacenaje (tipo "silo"). Se pudo confirmar que, por lo menos, algunos de los rasgos de la clase pequeña son, en efecto, tumbas por la presencia de huesos humanos en algunos ejemplares disturbados. Doutriaux también registró en Lari la presencia de dientes y huesos humanos en estructuras semejantes de muros agromortuorios (Doutriaux 2004:175-179). Se recuperó en cinco de estos sitios (YA-014, YA-030, CO-166, CO-168 y CO-169) cerámica Chiquero asociada con las tumbas en la parte alta de los muros. El más grande de estos complejos, el sitio YA-014, se ubica en la amplia pampa directamente por debajo de las laderas de Chiquero. Aparentemente, estos complejos de muros se aglutinaron lentamente, y durante el Formativo sus áreas probablemente fueron sólo una fracción de su eventual extensión, puesto que también se recuperó cerámica del Horizonte Medio, del Intermedio Tardío y del Horizonte Tardío. La presencia de la cerámica Chiquero asociada con las tumbas en YA-014 sugiere que la agricultura estaba diseminada durante el Formativo en el fondo del valle.

\section{Caza y Pastoreo en la Puna durante el Arcaico Terminal y el Formativo}

La prospección también ha documentado en la puna diez sitios con ocupaciones diagnósticas del Arcaico Terminal y/o Formativo. De estos diez sitios, cinco (YA-083, YA-087, YA-094, CO-104 y CO-159), se fecharon en base a la presencia de puntas de proyectil diagnósticas de estos períodos (Tipo 5C en la cronología regional de puntas, ver Klink y Aldenderfer 2003). De los cinco restantes, tres (YA-082, CO-105 y CO-152) se fecharon basados en la presencia de cerámica Chiquero y dos (YA-034 y CO-106) presentan ambos rasgos: puntas 5C y cerámica Chiquero. Los sitios de los períodos Arcaico Terminal y Formativo en la puna muestran una notable continuidad con las ocupaciones previas del Arcaico. Todos, a excepción de tres (dos al aire libre -CO-152 y CO-159, y un pequeño abrigo rocoso- YA-082), produjeron puntas de proyectil del período Arcaico Tardío o Terminal.

Registramos cuatro abrigos en la puna con componentes formativos (YA-082, YA-083, YA-094 y CO-106). Entre estos, tres (YA-082, YA-083 y YA-094) consistían de pequeñas concentraciones de artefactos asociadas a cortavientos. Un abrigo (YA-094), ubicado adyacente a una quebrada, presenta rasgos que sugieren durante el Formativo una función dual de caza y pastoreo (Figura 11). El área 


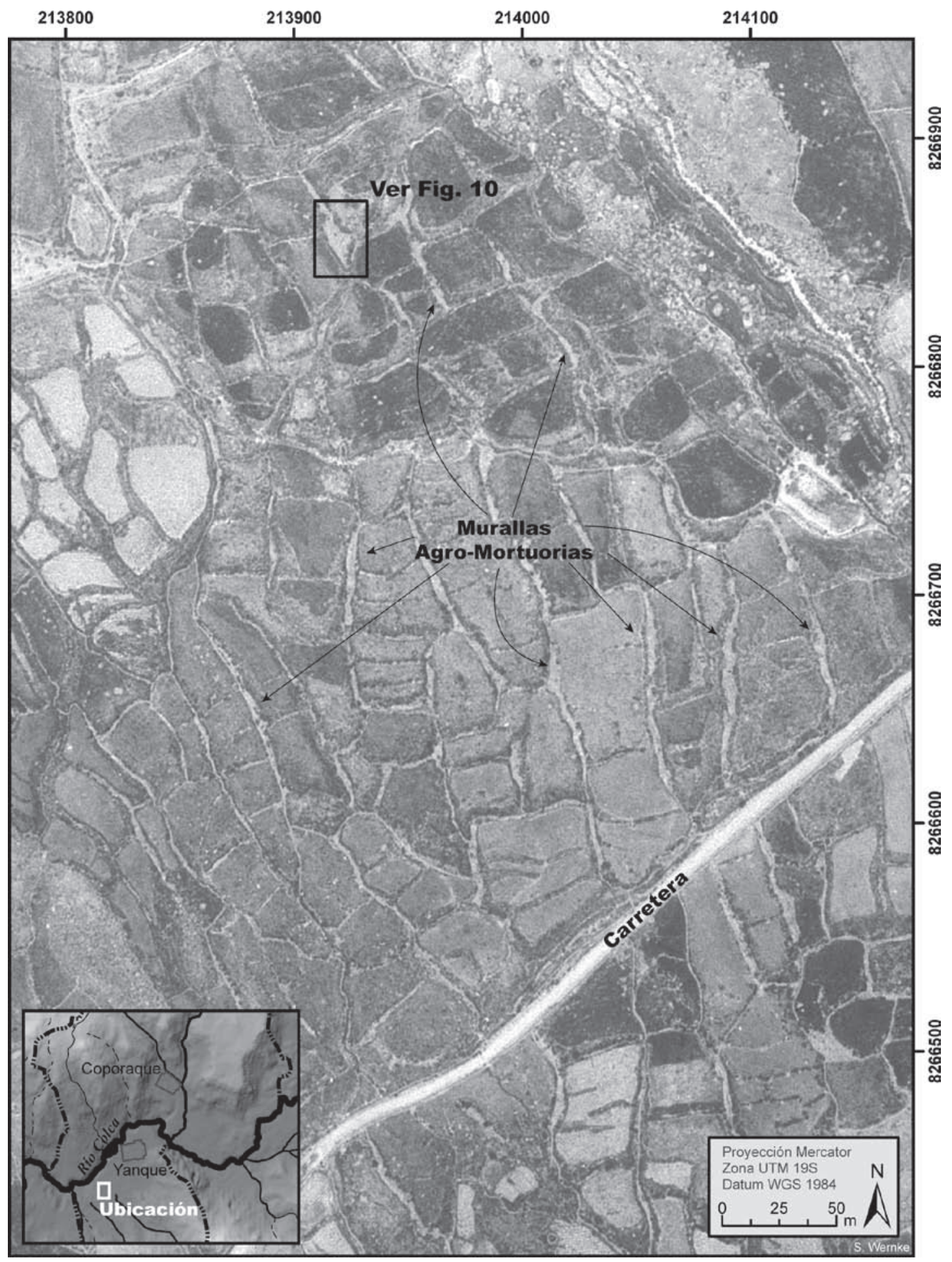

Figura 9. Foto aérea de murallas agro-mortuorias en el sitio YA-014.

Airphoto of agro-mortuary walls in the site YA-014. 


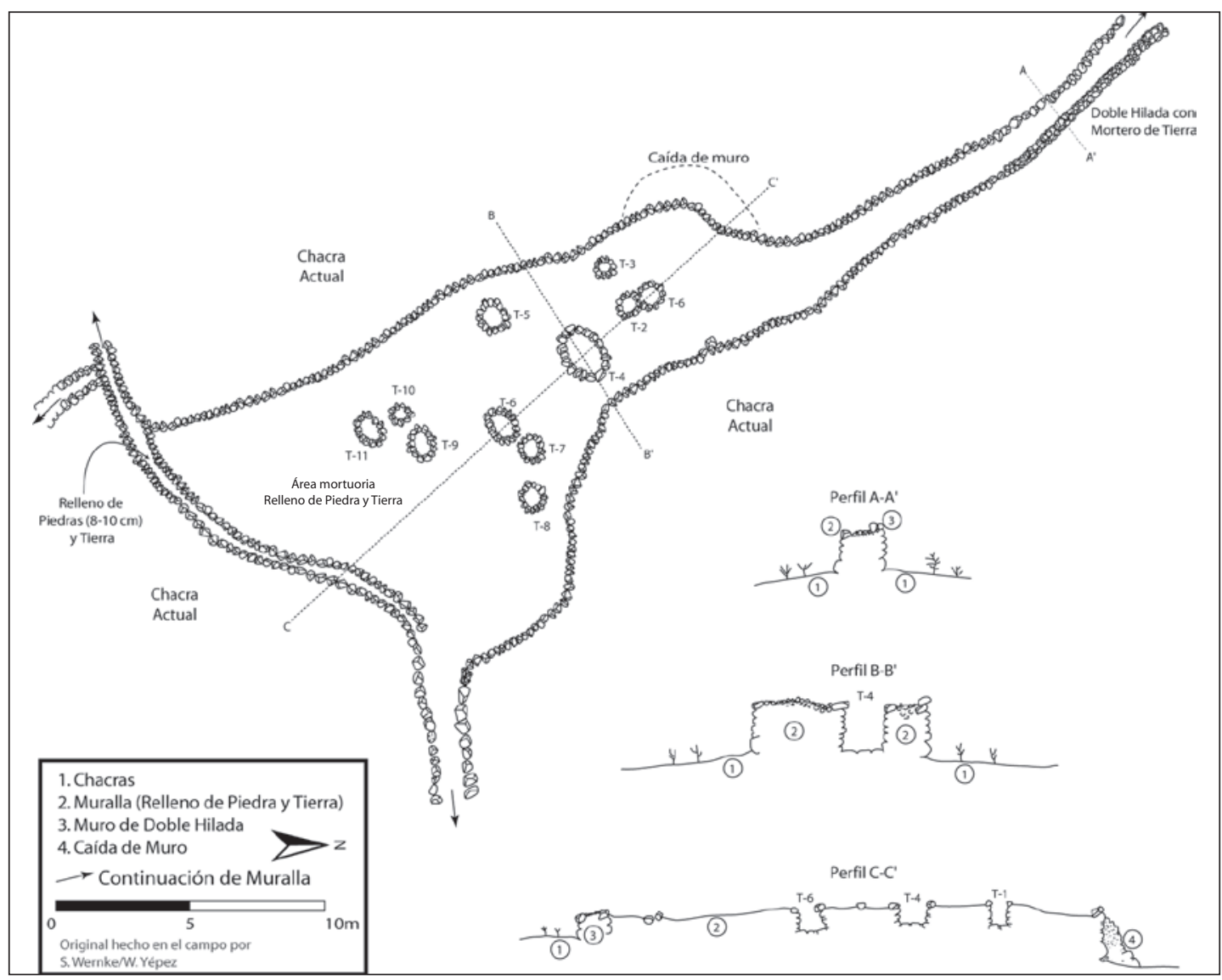

Figura 10. Plano de tumbas y otros rasgos de una muralla agro-mortuoria en YA-014.

Map of tombs and other features of an agro-mortuary wall in YA-014.

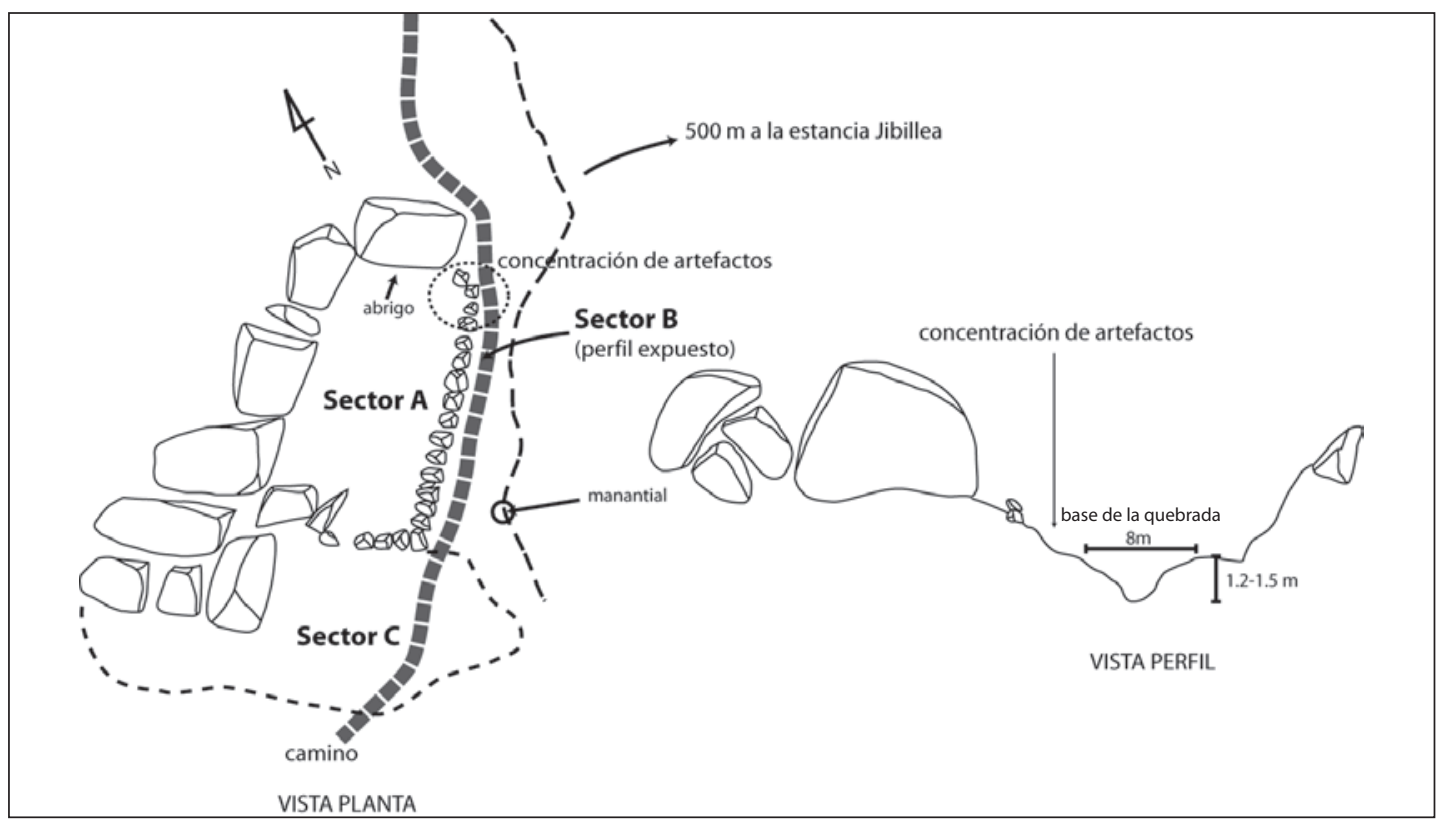

Figura 11. Croquis de YA-094. Original de W. Yépez.

Sketch of YA-094. Original by W. Yépez. 
frente al abrigo en este sitio (Sector A) pudo haber funcionado como un pequeño corral.

El cuarto sitio de abrigo -CO-106- es mucho más grande, y consiste de una serie de pequeñas cuevas formadas por un farallón en una quebrada grande (Figura 12). En este sitio se ha expuesto un perfil de $20 \mathrm{~m}$ con una estratigrafía visible hasta de 1,8 m de grosor. Además de las dos puntas recuperadas del Arcaico Terminal y Formativo, también se recolectaron puntas diagnósticas de los períodos Arcaico Temprano, Intermedio, Tardío y Terminal, así como un fragmento Chiquero.

Se registraron en la puna seis concentraciones líticas y cerámicas en contextos al aire libre, cinco de los cuales (YA-087, C=-104, CO-105, CO-152 y CO-159) consisten de dispersiones de 0.25 ha o menos. Sin embargo, un sitio al aire libre (YA-034) sobresale por su tamaño, densidad de material y larga continuidad de ocupación. Este sitio ocupa una superficie plana al lado de una pequeña quebrada, y también adyacente al sendero que cruza cerca del sitio de Chiquero (YA-032). Con un área de 2.47 ha y densamente cubierto con desechos de talla y otros artefactos líticos, YA-034 produjo más puntas de proyectil diagnósticas $(\mathrm{n}=35)$ que cualquier otro sitio de la prospección. La ocupación de este sitio también parece bastante larga, puesto que las puntas de proyectil recuperadas incluyen diagnósticos de los períodos Arcaico Temprano, Medio, Tardío y Terminal, así como de los períodos Arcaico Terminal hasta el Horizonte Medio. También se recuperó cerámica Chiquero. El sitio parece haber estado ocupado virtualmente desde las primeras ocupaciones humanas del valle hasta por lo menos el Horizonte Medio. Los gruesos perfiles expuestos en las áreas erosionadas son también testigos de la profundidad de la ocupación. Excavaciones en el futuro en este sitio deberán proveer importantes datos sobre la ocupación temprana del valle y la región.

\section{Discusión y Conclusiones}

Aunque los controles espaciales y cronológicos para el asentamiento agropastoril temprano del valle son rudimentarios, la prospección provee una línea de base a partir de la cual se puede trabajar, habiendo identificado una cerámica ampliamente diagnóstica del período Formativo, así como 30 sitios distribuidos a lo largo de todos los contextos fisiográficos y ecológicos importantes de

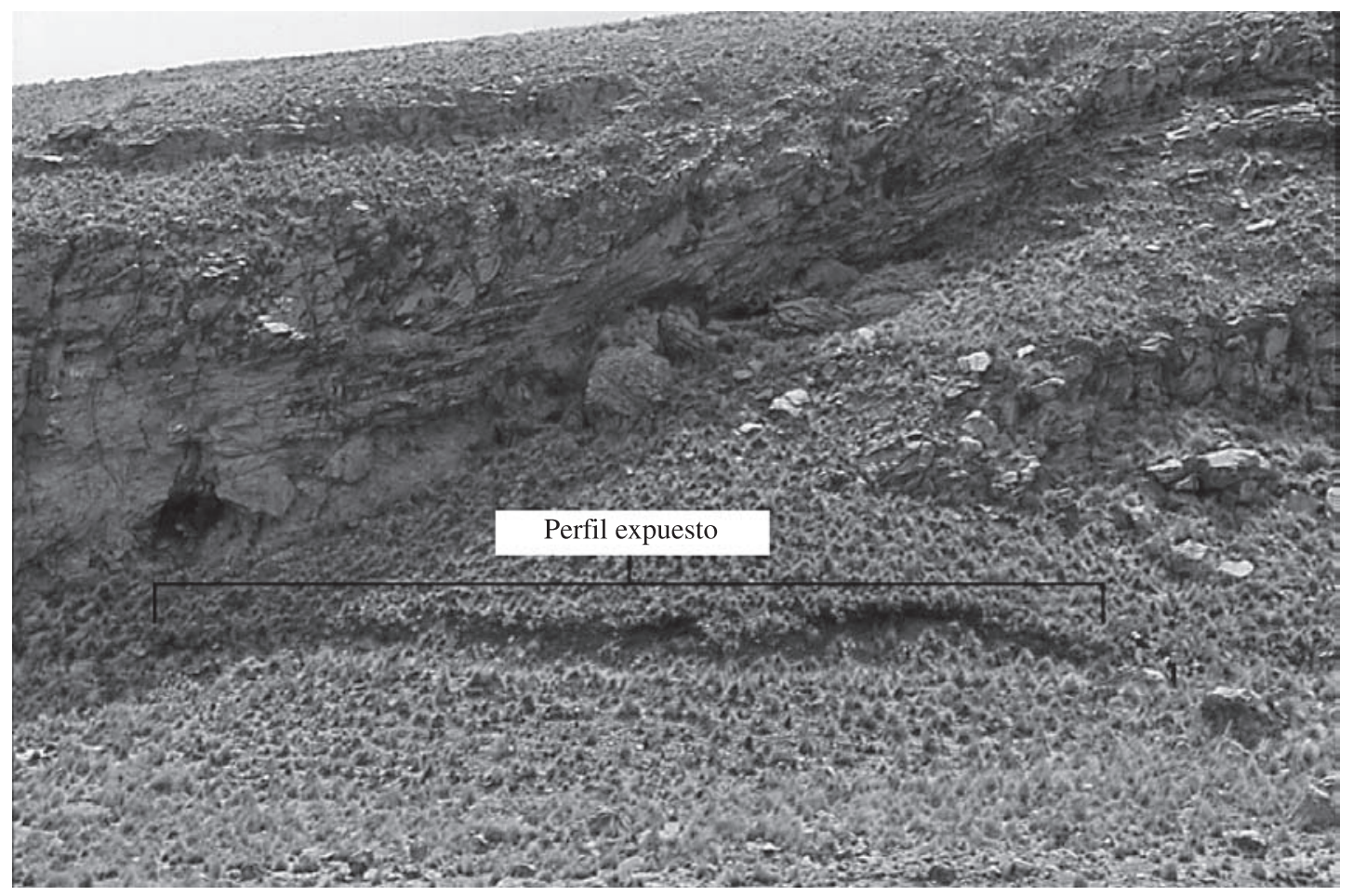

Figura 12. Sitio CO-106, mostrando la peña rocosa del abrigo y el perfil expuesto.

Site CO-106, showing the overhanging cliff of the rockshelter and the exposed profile. 
la porción central del valle. El asentamiento más grande (YA-032, Chiquero) se ubica en la zona suni, proporcionando acceso tanto al fondo del valle como a la zona de pastoreo en la puna. Aunque este sitio sobresale en términos de tamaño, parece que el período Formativo se caracteriza por un patrón de asentamiento indiferenciado. Asumiendo que el área de la prospección constituye una muestra representativa del valle (hipótesis respaldada con los datos de Tripcevich 2007 y Doutriaux 2004 para la parte alta y baja del valle respectivamente), el patrón observado muestra una distribución convexa en el tamaño de los asentamientos, lo que indicaría la integración de grupos sociopolíticos locales sin jerarquía espacial. No hay indicios de centros ceremoniales como se evidencian en la cuenca del Lago Titicaca. Pero no se debe concluir necesariamente que se trata de organización social acéfala. Los indicios de la infraestructura agrícola señalan por lo menos coordinación intercomunitaria en la construcción y mantenimiento de los elementos infraestructurales, los cuales en su conjunto acercan a la monumentalidad.

En comparación con las investigaciones previas, que se enfocaron a las terrazas agrícolas en las laderas del valle, la documentación recabada en nuestra prospección de asentamientos del período Formativo y rasgos agrícolas asociados en el fondo del valle, presenta un punto de vista marcadamente distinto acerca de la producción agrícola temprana. Treacy (1994:91-111), Brooks (1998) y Denevan (2001:172-173, 192-201) sugirieron que la agricultura temprana se concentró fundamentalmente a lo largo de las laderas superiores en la forma de sistemas de terrazas segmentadas y chacras en pendiente, junto con rasgos diseñados para el desvío del drenaje natural, como pequeñas represas y otros elementos de control de la escorrentía. Como observó Treacy, no hay evidencia de planificación supradoméstica en la construcción y organización de estos rasgos agrícolas en las laderas altas. De acuerdo a esta versión de la historia agrícola del valle, estos sistemas tempranos de control del drenaje fueron sustituidos por sistemas que sí requerían coordinación supradoméstica, en la forma de terrazas irrigadas en banca (Denevan 2001:172-173; Treacy 1994:91-111), o tal vez por una fase intermedia de terrazas en banca no irrigadas (Brooks 1998:374-386). Pero la cronología de estos cambios no era clara. Treacy (1994:92-105) sostuvo que las terrazas segmentadas en las laderas altas estuvieron en uso durante el Horizonte Medio. Brooks, a base de fechados radiocarbónicos de excavaciones más recientes, sostiene que las primeras terrazas agrícolas fueron construidas mucho más tempranamente, antes de los 2.400 a.C. (Brooks 1998:400-402, 405). Pero estos fechados son el resultado del promedio del carbón contenido en muestras de tierra y, por lo tanto, no son muy precisos o confiables.

A diferencia de estas investigaciones previas, nuestra prospección ha documentado las características del asentamiento y la producción agrícola ampliamente difundidas en el fondo del valle y en las laderas circundantes durante el período Formativo. Aunque el Formativo abarca 2.000 años, con estos hallazgos se puede establecer un marco temporal general para el comienzo de la producción agrícola en el valle -un rango cronológico que concuerde mejor con los fechados de los primeros desarrollos de la agricultura, el sedentarismo y las desigualdades sociales en otras partes de la región sur.

Asimismo, mientras que las chacras en pendiente y las terrazas segmentadas en las laderas altas del valle estuvieron en uso durante el Formativo, la escasez de artefactos o asentamientos de este periodo asociada a ellas sugiere que fueron usadas intermitentemente. En todo caso, ahora se ha establecido que fueron parte de un sistema productivo agrícola más grande que también se extendió al fondo del valle. Dado que la precipitación promedio queda al borde de los límites efectivos de los cultivos, es probable que las chacras en pendiente y las terrazas segmentadas fueran usadas de acuerdo a épocas de relativa abundancia de precipitación. Los datos paleoclimáticos del Lago Titicaca indican que durante el Formativo ocurrieron cuatro períodos de sequías importantes: (1) 1.550-1.400 a.C., (2) 950-850 a.C., (3) 450-250 a.C. y (4) 50 a.C.-250 d.C. (Abbott et al. 1997). La precipitación igual o superior a los niveles presentes ocurrió durante los períodos intermedios. Sin duda, los agricultores locales de la época tenían un conocimiento nítido de los cambios del régimen climático y el cultivo habría cambiado o expandido hasta incluir las chacras en pendiente y las terrazas segmentadas sobre las laderas altas durante tiempos de precipitación abundante. Por supuesto, los controles cronológicos disponibles son todavía demasiado gruesos como para evaluar este escenario, por lo que debe ser considerado hipotético. Pero la concentración de asentamientos y las características agrícolas tempranas del fondo del valle y de las laderas sugieren que la agricultura 
temprana estaba más ampliamente distribuida que lo que se planteó anteriormente.

Estos hallazgos, junto con los resultados importantes del estudio sobre la distribución de la obsidiana de la fuente Chivay por Tripcevich (2007; Tripcevich y Yépez 2009), señalan que el valle del Colca fue un centro de desarrollo y enlaces culturales más amplios e importantes durante el Formativo que lo que se reconoció anteriormente. Lo claro es que se trata del desarrollo de un sistema de asentamiento y producción agropastoril de carácter autóctono pero no aislado, basado en un patrón de pequeñas aldeas esparcidas por diversas zonas de producción, con mayor concentración en el fondo del valle. En cuanto a la infraestructura agrícola en el valle del Colca, la impresionante andenería irrigada posterior al periodo Formativo ha recibido mayor atención, pero ahora se han documentado extensivos sistemas de campos de cultivo en el fondo y las laderas del valle relacionados a las ocupaciones sedentarias tempranas. Las murallas agro-mortuorias que encierran los campos de cultivo en el fondo del valle constituyen una materialización de mucha labor colectiva y demuestran claramente coordinación corporativa de labor. En cuanto a sus funciones, las murallas agro-mortuorias claramente no fueron solamente espacios para los muertos o demarcaciones de campos de cultivo, sino parte de una tecnología de producción con propiedades beneficiosas para el cultivo. Tal como se ha documentado para los andenes (Denevan 1980:623; Donkin 1979:25-26; Treacy 1994:43-44), probablemente mitigaron los riesgos de escarchas y vientos, protegiendo los cultivos por su masa y forma, y funcionando como dispersores del calor durante las noches.

En este sentido, los hallazgos del presente estudio llaman atención a la importancia de la arqueología de paisaje para la comprensión de procesos sociales durante el Formativo. Los indicios tradicionales de patrones de asentamiento no captan la complejidad evidente en los rasgos de infraestructura agrícola. Claramente, el enfoque y inversión intensiva en la modificación antropogénica del paisaje del valle del Colca tiene sus raíces en esta época.

Agradecimientos: Esta investigación se hizo posible gracias a una beca de la Fundación WennerGren para Estudios Antropológicos (Beca $\mathrm{N}^{\mathrm{o}}$ 6431). Se agradece el apoyo logístico del Centro de Investigaciones Arqueológicas de Arequipa (CIARQ). Se realizó el trabajo de campo arqueológico bajo la autorización de la Resolución Directoral 615 (1999) del Instituto Nacional de Cultura. La fase analítica fue financiada por una beca de la Biblioteca Dumbarton Oaks y una beca de la Universidad de Wisconsin-Madison. Los planos fueron elaborados con el apoyo y facilidades del Laboratorio de Investigaciones de Análisis Espacial (SARL) de Vanderbilt University. La colaboración de los miembros del equipo, Lic. Ericka Guerra Santander (co-edirectora), Lic. Willy Yépez Alvarez, y Lic. Erika Simborth Lozada trascendió lo técnico y formó una parte íntegra del contenido intelectual del proyecto. Se agradece profundamente a nuestros anfitriones en Yanque, don Gerardo Huaracha Huaracha y su doña Luisa Cutipa de Huaracha, y a todas las autoridades y miembros de las comunidades de Yanque y Coporaque por su gentil hospitalidad y buena voluntad hacia nuestro proyecto. Se agradece al Dr. Félix Palacios Ríos por su redacción del manuscrito. Las sugerencias y observaciones de tres evaluadores anónimos fortificaron el rigor del producto final. Pese al apoyo de otros, cualquier equivocación es responsabilidad única del autor.

\section{Referencias Citadas}

Abbott, M.B., M.W. Binford, M. Brenner y K.R. Kelts

1997 A 3500 14C yr high-resolution record of water-level changes in Lake Titicaca, Bolivia/Peru. Quaternary Research 47:169-180.

Aldenderfer, M.S.

1998 Montane Foragers: Asana and the South-Central Andean Archaic. University of Iowa Press, Iowa City.

Bandy, M.S.

2001 Population and History in the Ancient Titicaca Basin. Doctoral Dissertation, University of California, Berkeley. University Microfilm, Ann Arbor. 2004a Fissioning, scalar stress, and social evolution in early village societies. American Anthropologist 106:322333.

2004b Trade and social power in the southern Titicaca Basin Formative. En Foundations of Power in the Prehispanic Andes, Archeological Papers of the American Anthropological Association, tomo 14, editado por K.J. Vaughn, D. Ogburn y C.A. Conlee, pp. 91-111.

Brooks, S.O.

1998 Prehistoric Agricultural Terraces in the Río Japo Basin, Colca Valley, Peru. Doctoral Dissertation, University of Wisconsin-Madison. University Microfilm, Ann Arbor. 
Brooks, S.O., M.D. Glascock y M. Giesso

1997 Source of volcanic glass for ancient Andean tools. Nature 386:449-450.

Browman, D.L.

1981 New light on Andean Tiwanaku. American Scientist 69(4):408-419.

Burger, R.L., F. Asaro, G. Salas y F. Stross

1998 The Chivay obsidian source and the geological origin of Titicaca Basin-type obsidian artifacts. Andean Past 5:203-223.

Burger, R.L., K.L.M. Chávez y S.J. Chávez

2000 Through the glass darkly: prehispanic obsidian procurement and exchange in southern Peru and northern Bolivia. Journal of World Prehistory 14:267-362.

Cardona Rosas, A.

2002 Arqueología de Arequipa: de sus Albores a los Incas. CIARQ, Arequipa.

Chávez, K.L.M.

1988 The significance of Chiripa in Late Titicaca Basin developments. Expedition 30:17-26.

Chávez, S.J.

1992 The Conventionalized Rules in Pucara Potter Technology and Iconography: Implications for Socio-Political Development in the Northern Lake Titicaca Basin. Doctoral Dissertation, Michigan State University. University Microfilm, Ann Arbor. de la Vera Cruz Chávez, P.

1987 Cambios en los patrones de asentamiento y el uso y abandono de los andenes en Cabanaconde, Valle del Colca, Perú. En Pre-Hispanic Agricultural Fields in the Andean Region, B.A.R. International Series 359(i), editado por W.M. Denevan, K. Mathewson y G.W. Knapp, pp. 89-128. Oxford.

1988 Estudio Arqueológico en el Valle de Cabanaconde, Arequipa. Tesis para optar al grado de Bachillerato de Arqueología, Universidad Católica Santa María, Arequipa. 1989 Cronología y Corología de la Cuenca del Río CamanáMajes-Colca-Arequipa. Tesis para optar al grado de Licenciado de Arqueología, Universidad Católica Santa María, Arequipa.

Denevan, W.M.

1980 Tipología de configuraciones agrícolas prehispánicas. América Indígena 40:619-652.

2001 Cultivated Landscapes of Native Amazonia and the Andes. Oxford University Press, Oxford.

Dillehay, T.D. y L. Núñez

1988 Camelids, caravans, and complex societies in the south-central Andes. En Recent Studies in Pre-Columbian Archaeology, B.A.R. International Series 421, editado por N.J. Saunders y O. de Montmollin, pp. 603-634.

Donkin, R.A.

1979 Agricultural Terracing in the Aboriginal New World. University of Arizona Press, Tucson.

Doutriaux, M.

2004 Imperial Conquest in a Multiethnic Setting: The Inka Occupation of the Colca Valley, Peru. Doctoral Dissertation, University of California, Berkeley. University Microfilm, Ann Arbor.

Hastorf, C.A., editor

1999 Early Settlement at Chiripa, Bolivia: Research of the Taraco Archaeological Project. University of California, Berkeley.
Janusek, J.W.

2004 Tiwanaku and Its precursors: recent research and emerging perspectives. Journal of Archaeological Research 12:121-183.

2008 Ancient Tiwanaku. Cambridge University Press, Cambridge; New York.

Janusek, J.W. y A.L. Kolata

2004 Top-down or bottom-up: rural settlement and raised field agriculture in the Lake Titicaca Basin, Bolivia. Journal of Anthropological Archaeology 23:404-430.

Klarich, E.A.

2005 From the Monumental to the Mundane: Defining Early Leadership Strategies at Late Formative Pukara, Peru. Doctoral Dissertation, University of California, Santa Barbara. University Microfilm, Ann Arbor.

2009 Pukara: Investigaciones de la temporada 2001 y un nuevo modelo para el desarrollo del sitio. Andes: Boletín del Centro de Estudios Precolombinos de la Universidad de Varsovia 7:23-31.

Klink, C. y M.S. Aldenderfer

2005 A projectile point chronology for the south-central Andean highlands. En Advances in Titicaca Basin Archaeology I, editado por C. Stanish, A. Cohen y M.S. Aldenderfer, pp. 25-54. Cotsen Institute of Archaeology, Los Angeles.

Kolata, A.L.

1993 The Tiwanaku: Portrait of an Andean Civilization. Blackwell, Cambridge.

Malpass, M.A. y P. de la Vera Cruz Chávez

1990 Cronología y secuencia de la cerámica de Chijra, valle del Colca. Gaceta Arqueológica Andina 18/19:41-57.

Neira Avendaño, M.

1961 Los Collaguas. Tesis para optar al grado de Magister en Arqueología, Universidad Nacional de San Agustín, Arequipa.

1986 Excavaciones arqueológicas en las ruinas de Chishra (Chijra), Coporaque. En The Cultural Ecology, Archaeology, and History of Terracing and Terrace Abandonment in the Colca Valley of Southern Peru. Technical Report to the National Science Foundation and the National Geographic Society, tomo I, editado por W.M. Denevan, pp. 167-197. Department of Geography, University of Wisconsin-Madison, Madison.

1990 Arequipa prehispánica. En Historia General de Arequipa, editado por M. Neira Avendaño, G. Galdos Rodríguez, A. Málaga Medina, E. Quiroz Paz Soldán y J.G. Carpio Muñoz, pp. 5-213. Fundación M.J. Bustamante de la Fuente, Arequipa.

Neira Avendaño, M. y A. Cardona Rosas

2000-2001 El periodo Formativo en el área de Arequipa. En Proyecto Arqueológico Condesuyus, editado por M. Ziólkowski y A. Belán Franco, pp. 27-60. Universidad de Varsovia.

Oquiche Hernani, A.A.

1991 La Ocupación Collagua e Inca en el Sector de Achoma, Valle del Colca. Tesis para optar al Bachillerato de Arqueología, Universidad Católica Santa María, Arequipa.

Shea, D.E.

1987 Preliminary discussion of prehistoric settlement and terracing at Achoma, Colca Valley, Peru. En Pre-Hispanic Agricultural Fields in the Andean Region, B.A.R. International Series 359(i), editado por W.M. Denevan, K. Mathewson y G.W. Knapp, pp. 67-88. 
Stanish, C.

1997 Archaeological Survey in the Juli-Desaguadero Region of Lake Titicaca Basin, Southern Peru. Field Museum of Natural History, Chicago.

2003 Ancient Titicaca: The Evolution of Complex Society in Southern Peru and Northern Bolivia. University of California Press, Berkeley.

Stanish, C., R.L. Burger, L.M. Cipolla, M.D. Glascock y E. Quelima

2002 Evidence for early long-distance obsidian exchange and watercraft use from the southern Lake Titicaca Basin of Bolivia and Peru. Latin American Antiquity 13:444-454.

Stanish, C., L. Steadman y M.T. Seddon

1994 Archaeological Research at Tumatumani, Juli, Peru. Field Museum of Natural History, Chicago.

\section{Treacy, J.M.}

1994 Las Chacras de Coporaque: Andenería y Riego en el Valle del Colca. Instituto de Estudios Peruanos, Lima.

Tripcevich, N.

2007 Quarries, Caravans, and Routes to Complexity: Prehispanic Obsidian in the South-Central Andes. Doctoral Dissertation, University of California, Santa Barbara. University Microfilm, Ann Arbor.

Tripcevich, N. y A. Mackay

2011 Procurement at the Chivay obsidian source, Arequipa, Perú. World Archaeology 43:271-297.
Tripcevich, N. y W. Yépez Alvarez

2009 La fuente de obsidiana "Chivay" y su posición en los Andes Sur Centrales. Andes: Boletín del Centro de Estudios Precolombinos de la Universidad de Varsovia 7:127-152.

Wernke, S.A.

2003 An Archaeo-History of Andean Community and Landscape: The Late Prehispanic and Early Colonial Colca Valley, Peru. Doctoral Dissertation, University of Wisconsin-Madison. University Microfilm, Ann Arbor.

2006a Collagua 'eco-logistics': intermediate elites and hybrid community structures in the Colca Valley, Peru. En Intermediate Elites in Pre-Columbian States and Empires, editado por C.M. Elson y R.A. Covey, pp. 175-211. University of Arizona Press, Tucson.

2006b The politics of community and Inka statecraft in the Colca Valley, Peru. Latin American Antiquity 17:177-208. 2007 Negotiating community and landscape in the Peruvian Andes: a trans-conquest view. American Anthropologist 109:130-152.

2009 La interfaz política-ecológica en el valle del Colca durante la época Inkaica. Andes: Boletín del Centro de Estudios Precolombinos de la Universidad de Varsovia 7:587-614. 